\title{
Evidences in the treatment of idiopathic normal pressure hydrocephalus
}

\author{
Matheus Fernandes de Oliveira ${ }^{1 *}$, Rodolfo Casimiro Reis² ${ }^{2}$ Evelinda Marramon Trindade ${ }^{3}$, Fernando Campos Gomes Pinto ${ }^{4}$ \\ ${ }^{1}$ Neurosurgeon, Master in Health Sciences, Instituto de Assistência Médica ao Servidor Público Estadual (IAMSPE), São Paulo, SP, Brazil \\ ${ }^{2}$ Neurosurgeon at IAMSPE, São Paulo, SP, Brazil \\ ${ }^{3} \mathrm{PhD}$ in Evaluation and Incorporation of New Technologies in the Brazilian Health Services' System, Faculdade de Medicina, Universidade de São Paulo (FMUSP), São Paulo, SP, Brazi \\ ${ }^{4}$ Full Professor of Neurology, FMUSP, São Paulo, SP, Brazi
}

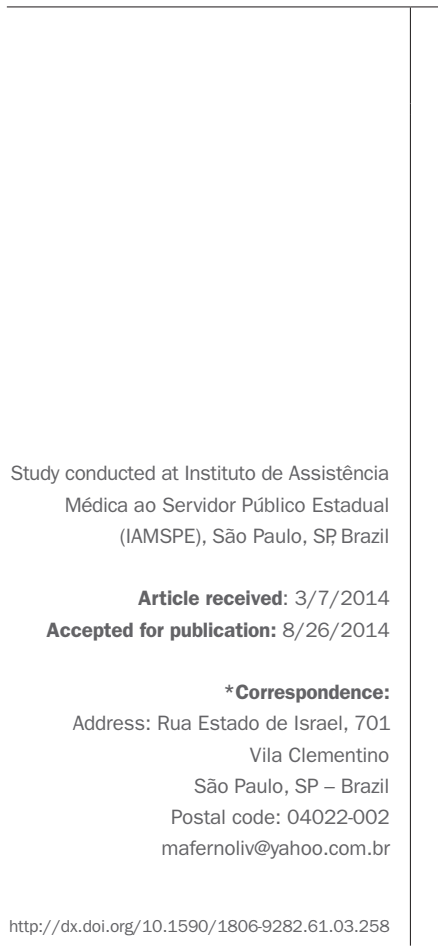

\section{SUMmARY}

Introduction: idiopathic normal pressure hydrocephalus (INPH) is characterized by gait apraxia, cognitive dysfunction and urinary incontinence. There are two main treatment options: ventriculoperitoneal shunt (VPS) and endoscopic third ventriculostomy (ETV). However, there are doubts about which modality is superior and what type of valve should be applied. We are summarizing the current evidence in INPH treatment.

Methods: an electronic search of the literature was conducted on the Medline, Embase, Scielo and Lilacs databases from 1966 to the present to obtain data published about INPH treatment.

Results: the treatment is based on three pillars: conservative, ETV and VPS. The conservative option has fallen into disuse after various studies showing good results after surgical intervention. ETV is an acceptable mode of treatment, but the superiority of VPS has made the latter the gold standard.

Conclusion: well-designed studies with a high level of appropriate evidence are still scarce, but the current gold standard for treatment of INPH is conducted using VPS.

Keywords: normal pressure hydrocephalus, advanced treatment, neuroendoscopy, ventriculoperitoneal shunt.

\section{INTRODUCTION}

Idiopathic normal pressure hydrocephalus (INPH) is characterized by progressive gait apraxia, cognitive dysfunction and urinary incontinence (Hakim-Adams syndrome). ${ }^{1-6}$ INPH consists of communicating hydrocephalus (shown by CT scan or MRI of the brain) and pressure within the normal range in the cerebrospinal fluid $\left(7-24 \mathrm{~cm} \mathrm{H}_{2} \mathrm{O}\right){ }^{4-10}$ The triad of Hakim-Adams syndrome is present in approximately $50 \%$ of cases, however, only one or a combination of two symptoms should be considered for investigation and diagnosis. It is a differential diagnosis for most dementia syndromes and mainly affects the elderly population, being one of the potential causes of potentially reversible dementia. ${ }^{4-10}$ The incidence is approximately 6 per 100,000 and the prevalence is 22 per 100,000. There are associations with hypertension, cerebrovascular disease and Alzheimer's. ${ }^{11-15}$

Generally, surgical treatment of patients with INPH is accepted as necessary because surgery has been associated with a positive impact on the progress of the disease. Currently, there are two main treatment options: ventriculoperitoneal shunt (VPS) and endoscopic third ventriculostomy (ETV). ${ }^{8,11-15,41}$ The most accepted and most conducted option is VPS with implantation of the programmable valve. However, there are doubts about which modality is superior and what type of valve should be applied.

Below, we summarize the current evidence in the treatment of idiopathic normal pressure hydrocephalus and critically review the applicable literature.

\section{Methods}

An electronic search of the literature was conducted on the Medline, Embase, Scielo, and Lilacs databases from 1966 to the present to obtain data published about INPH treatment. The following search strategies were used: "normal pressure hydrocephalus" or "idiopathic normal pressure hydrocephalus" and "treatment" or "management" or "outcome" and "shunt" or "ventriculoperito- 
neal shunt" or "diversion" or "endoscopic third ventriculostomy" or "third ventriculostomy" or "conservative" or "nonsurgical".

All works in the Portuguese, Spanish and English languages discussing the subjects above were selected. The search found 938 manuscripts that were subsequently limited to articles describing treatment methods and evolution for patients with INPH. We excluded manuscripts discussing other types of hydrocephalus or patients with a suspected diagnosis of INPH. The objective was to summarize current knowledge about the treatment of normal pressure hydrocephalus.

\section{Results}

\section{Surgery, rehabilitation or conservative treatment}

The treatment of INPH based on the evidence can be categorized into three pillars: conservative treatment, VPS and ETV. ${ }^{11-15}$ The conservative option has fallen into disuse after various studies showing good results after surgical intervention. Thus, it is widely accepted that surgical treatment of patients with INPH is mandatory because surgery has been associated with a positive impact on the course of the disease, which affects the quality of life of patients and caregivers. ${ }^{16-22}$

Rehabilitation strategies should always be included in the treatment of INPH. However, it is considered a supplementary treatment option.

\section{Endoscopy or ventricular shunt}

VPS is by far the most common method used to treat INPH worldwide. Since INPH is understood as a communicating hydrocephalus, ETV has been somewhat discouraged as treatment. ${ }^{16-22}$

However, the ventricular shunt presents both the inconvenience of a prosthetic implant and medium and long term risk of complications that require reoperation, such as infection, dysfunction and overdrainage. ${ }^{23-30}$ Records from the United Kingdom show a reoperation rate of $22 \%$ in five years after treatment of hydrocephalus in adults. ${ }^{14}$ The siphon effect, which is responsible for overdrainage, can be partially controlled by an anti-siphon device associated with the valve system, a flow regulated valve or a valve with programmable pressure. ${ }^{31-35}$

Hypothetically, if patients could be treated with ETV having the same long-term effects compared to VPS, the risk of long-term complications would be reduced, which would be an advantage for elderly patients, who often have comorbidities. ${ }^{23-30}$

As such, an Italian multicenter retrospective study, published in 2008 by Gangemi et al., ${ }^{15}$ caused great de- bate in the neurosurgical community. This study demonstrated a $69.1 \%$ success rate for endoscopic treatment in 110 patients with INPH after a follow-up period of at least 2 years. ${ }^{5}$ There was no correlation between the success rate and age or size of the ventricle. The neurological improvement rate was higher in patients at the start of clinical symptoms for gait disturbances. During surgery, the reappearance of normal brain pulsations and the observation of the movements of the third ventricle floor after ETV were associated with a good result. Complications occurred in 7 (6.4\%) patients and 4 (3.6\%) patients needed a second endoscopic procedure. Therefore, the authors concluded that ETV was an effective and safe option for the treatment of INPH. ${ }^{5}$

However, this study was heavily criticized as, among other reasons, there was no clear distinction between cases of INPH and possible cases of secondary NPH; the functional predictive test was predictive intracranial pressure monitoring, instead of the tests which are most widely used in the literature, such as the Tap Test (TT), the lumbar infusion test and external lumbar drainage for 72 hours. ${ }^{16}$

Additionally, a study in 2013 compared VPS and ETV and found higher perioperative mortality rates and complications in the ETV group. ${ }^{30}$ Randomized prospective studies are needed to clarify some results that are still contradictory.

Different types of shunt may be used, but the most common is VPS, whose effectiveness varies between 33 and $90 \%{ }^{32-38}$ This disparity occurs due to the variation in the selection of patients in different studies and the absence of a single, universally accepted scale for analysis of improvement in the patient. The rate of major complications (severe intraoperative hemorrhage, subdural hematoma, neurologic deficits, epilepsy, cardiac arrhythmias, hypothalamic dysfunction, cerebrospinal fluid leakage, infection) occurs in about $6 \%$ of patients after surgery. ${ }^{39-45}$

Pujari et al. ${ }^{36}$ retrospectively analyzed 55 patients for at least three years after surgery and reported that surgical revisions were needed in up to 53\% patients with VPS. However, despite the need for revisions, patients generally maintained clinical improvements in the long term. ${ }^{36}$

Pinto et al. ${ }^{16}$ conducted a randomized clinical trial to clarify doubts comparing radiological standards and clinical progression according to the treatment method adopted (VPS vs. ETV). Both modes of treatment for INPH achieved benefits, while VPS was shown to be superior (76 vs. 50\%). In the VPS group, however, there was $19 \%$ of complications (subdural hematoma) compared with no 
complication in the ETV group. In this study, the valve used was a fixed pressure valve. ${ }^{16}$

Fixed pressure valve, programmable pressure valve or flow-regulated valves

The ventriculoperitoneal shunt may be conducted using fixed pressure valves, programmable pressure valves and pressure-regulated valves. They differ in the cerebrospinal fluid (CSF) flow mechanism. In fixed pressure valves, the CSF flows through the shunt when the intracranial pressure reaches a fixed threshold. In programmable valves, this threshold may be adjusted according to the patient's symptoms. Thus, the most adequate pressure can be achieved for each patient. In flow-regulated valves, the CSF flow is continuous, regardless of pressure. These valves may differ in price, given that programmable valves and flow-regulated valves involve more advanced technology and are more expensive. ${ }^{32-38}$

Although the concept of normal pressure suggests that the CSF pressure is normal, there is in fact an intermittent variation in CSF pressure with a normal average. Qualitative evaluation through epidural monitoring reveals Lundberg B waves with spikes of up to $50 \mathrm{mmHg}$, occurring mainly at night. These waves reflect the dynamics of the production, circulation and absorption of CSF, indicating that cerebral compliance is abnormal..$^{72,16,45}$

Programmable valves are increasingly recommended for the treatment of INPH, as the pressure in the drainage system may be adjusted according to patient's symptoms in order to achieve maximum improvement with minimal complications, such as overdrainage due to the siphoning effect. ${ }^{45}$

Many works about the use of programmable valves are known. The Codman Medos ${ }^{\circledR}$ valve allows pressure adjustments in 18 stages between 30 and $200 \mathrm{~mm} \mathrm{H}_{2} \mathrm{O}$. A series of 90 patients was reported with satisfactory clinical results. Another retrospective study was published with 583 patients with hydrocephalus due to various causes treated with a Codman Hakim ${ }^{\circledR}$ programmable valve. The proGAV ${ }^{\circledR}$ (Aesculap) and Polarys ${ }^{\circledR}$ (Sophysa) valves also have evidence supported in the literature. ${ }^{45}$

Another valve is the Strata ${ }^{\circledR}$, also widely employed, including in pediatric patients. Recently, the Strata ${ }^{\circledR}$ was the subject of a study of 72 patients with INPH with appropriate control of symptoms and long term durability. Another study of 24 patients reported improvements in $83 \%$ with a $20.8 \%$ rate of complications, including reoperations in 5 patients. ${ }^{45}$

Various studies have attempted to compare the results of fixed pressure and programmable pressure valves. Despite fixed pressure valves being used with good results, there are complications caused by overdrainage in a significantly higher percentage. Some studies suggest that the advantage of reprogramming programmable valves is not translated into a reduction in surgical revisions and, therefore, fixed pressure valves could be used. ${ }^{39-45}$

Given that the average pressure of the CSF in INPH is normal, some authors suggest that the ideal valve should be directed at the flow of CSF and not the pressure. Therefore, flow-regulated valves would be more appropriate. The commercial name is Orbis Sigma ${ }^{\circledR}$. However, up to now, there have been no randomized clinical trials comparing and clearly determining the effect of these valves with others and programmable valves are considered the gold standard treatment for INPH (Table 1). ${ }^{6-11,17,18}$

An important point is that no study of cost effectiveness involving INPH and its treatment methods has been conducted up to the present.

TABLE 1 Different studies of idiopathic normal pressure hydrocephalus.

\begin{tabular}{|c|c|c|c|c|c|}
\hline Author & Year & Study type & Test applied & Assessment & Success (\%) \\
\hline \multirow[t]{2}{*}{ Pinto et al. ${ }^{16}$} & \multirow[t]{2}{*}{2013} & Randomized clinical & \multirow[t]{2}{*}{$\pi$} & \multirow[t]{2}{*}{ fpVPS vs. ETV } & 76 VPS \\
\hline & & trial & & & $50 \mathrm{ETV}$ \\
\hline Oliveira et al. ${ }^{45}$ & 2013 & Prospective & $\pi$ & PVPS & 83 \\
\hline Zemack et al. ${ }^{17}$ & 2002 & Retrospective & - & pVPS & 78.9 \\
\hline Gangemi et al. ${ }^{5}$ & 2008 & Retrospective & - & ETV & 69.1 \\
\hline McGirt et al. ${ }^{7}$ & 2005 & Prospective & LDT & pVPS & 75 \\
\hline Boon et al. ${ }^{6}$ & 1998 & $\begin{array}{l}\text { Randomized clinical } \\
\text { trial }\end{array}$ & - & fpVPS & 64 \\
\hline \multirow[t]{2}{*}{ Weiner et al. ${ }^{10}$} & \multirow[t]{2}{*}{1995} & \multirow[t]{2}{*}{ Retrospective } & \multirow[t]{2}{*}{-} & \multirow[t]{2}{*}{ frVPS vs. fpVPS } & 90 frVPS \\
\hline & & & & & 90 fpVPS \\
\hline Vanneste et al. ${ }^{9}$ & 1992 & Retrospective & - & fpVPS & 74 \\
\hline
\end{tabular}

TT: tap test; LDT: lumbar drainage test; pVPS: programmable VPS; fpVPS: fixed pressure VPS; frVPS: flow-regulated VPS. 


\section{Discussion}

The identification of patients with INPH and the implementation of effective treatment are current challenges for neurosurgeons, as this is a disorder classified as a type of dementia that affects the elderly and can be reversed if diagnosed and properly treated. With improvements in quality of life and consequent increase in life expectan$c y$, it is expected that a greater number of elderly people will suffer from the disease. In 2008, incidence and prevalence were calculated in a stable community of 220,000 inhabitants in Norway, with values of 5.5/100,000 and $22 / 100,000$, respectively. ${ }^{20,24,29}$

Treatment is mainly aimed at restoring the patient's functional capacity. Thus, the decision about whether surgery should be conducted requires considerations over the probability of improvement through the use of tools for forecasting postoperative results. Up to now, no diagnostic test is $100 \%$ effective for diagnosis and predicting postoperative results. Favorable indicators of postoperative improvement include: early onset of gait disorders and onset of symptoms for less than six months. Adverse indicators include: the absence of changes in gait or its emergence after the onset of the disease, early onset dementia, mild to severe dementia, dementia for more than two years, diffuse brain atrophy and severe impairment of the white matter..$^{30-34}$

The pathophysiology of INPH is still not completely understood. A widely accepted theory is low venous compliance, especially frontal, in the basal ganglia and thalamus. This has been demonstrated in the superior sagittal sinus with manometry studies, affecting circulation and absorption of CSF in the sub-arachnoid granulations. Furthermore, there are various diseases that present the same symptoms as the classic NPH triad. This contributes to the heterogeneity of the groups evaluated. ${ }^{18-20,27,34,40}$

The details outlined above make the literature on the surgical treatment of INPH exist largely in the form of retrospective cohort studies, and high-level studies are still scarce. In addition, the complex and diverse clinical pathophysiology helps to generate heterogeneous patient samples even in well-designed studies. The response to the shunt is often variable due to the heterogeneity of the sample, which may be contaminated with other diseases that cause the same symptoms as INPH. Many series reported by Vanneste, McGirt, Pinto, Zemack and other authors ${ }^{7,9,16,17}$ disagree in terms of methodology, inclusion criteria, clinical and radiological evaluation and conclusions. These dramatically different results illustrate how difficult it is to manage these patients. ${ }^{7,9,16,17}$
A growing concern that also needs to be approached is the bias present in scientific publications. This bias may be present in selection, analysis and/or conduct. Many studies are sponsored by large companies and authors may have conflicts of interest. In a setting where a major investment is needed to provide adequate treatment, an independent and lucid assessment is also a challenge.

\section{Conclusion}

Well-designed studies with a high level of evidence are still scarce, and the current gold standard treatment for INPH is conducted using ventricular shunts with programmable valves. VPS with fixed pressure valves and ETV may be secondary options, and the role of flow-regulated valves is yet to be determined.

\section{Resumo}

Evidências no tratamento da hidrocefalia de pressão normal idiopática.

Introdução: a hidrocefalia de pressão normal idiopática (HPNI) é caracterizada por apraxia da marcha, disfunção cognitiva e incontinência urinária. Existem duas principais opções terapêuticas: derivação ventriculoperitoneal (DVP) e terceiro ventriculostomia endoscópica (TVE). No entanto, há dúvidas sobre qual modalidade é superior e que tipo de válvula deve ser aplicada. Este artigo resume as evidências atuais no tratamento de HPNI.

Métodos: uma busca eletrônica da literatura foi realizada nas bases de dados Medline, Embase, SciELO e Lilacs, de 1966 até o momento presente para revelar os dados publicados sobre o tratamento da HPNI.

Resultados: o tratamento é baseado em três pilares: conservador isolado, TVE e DVP. A opção conservadora caiu em desuso depois de vários estudos revelarem bons resultados após a intervenção cirúrgica. A TVE é uma modalidade de tratamento aceitável, mas a superioridade da DVP torna-a o padrão-ouro.

Conclusão: estudos com evidência de alto nível, adequados e bem desenhados, ainda são escassos. O tratamento padrão-ouro atual de HPNI é realizado com DVP.

Palavras-chave: hidrocefalia de pressão normal, tratamento avançado, neuroendoscopia, derivação ventriculoperitoneal.

\section{References}

1. Adams RD, Fisher CM, Hakim S, Ojemann RG, Swett WH. Symptomatic occult hydrocephalus with "normal" cerebrospinal-fluid pressure: a treatable syndrome. N Engl J Med. 1965;273:117-26. 
2. Hakim CA, Hakim R, Hakim S. Normal-pressure hydrocephalus. Neurosurg Clin North Am. 2001;12:761-73.

3. Hakim S, Adams RD. The special clinical problem of symptomatic hydrocephalus with normal cerebrospinal fluid pressure. Observations on cerebrospinal fluid hydrodynamics. J Neurol Sci. 1965;2:307-27.

4. Toma AK, Stapleton S, Papadopoulos MC, Kitchen ND, Watkins LD. Natural history of idiopathic normal-pressure hydrocephalus. Neurosurg Rev. 2011;34:433-9.

5. Gangemi M, Maiuri F, Naddeo M, Godano U, Mascari C, Broggi G, et al. Endoscopic third ventriculostomy in idiopathic normal pressure hydrocephalus: an Italian multicenter study. Neurosurgery. 2008;63:62-7; discussion 67-9.

6. Boon AJ, Tans JT, Delwel EJ, Egeler-Peerdeman SM, Hanlo PW, Wurzer HA, et al. Dutch Normal-Pressure Hydrocephalus Study: randomized comparison of low-and medium-pressure shunts. J Neurosurg. 1998;88:490-5.

7. McGirt MJ, Woodworth G, Coon AL, Thomas G, Williams MA, Rigamonti D. Diagnosis, treatment, and analysis of long-term outcomes in idiopathic normal-pressure hydrocephalus. Neurosurgery. 2008;62(Suppl 2):670-7.

8. Petersen RC, Mokri B, Laws ER. Surgical treatment of idiopathic hydrocephalus in elderly patients. Neurology. 1985;35:307-11.

9. Vanneste J, Augustijn P, Dirven C, Tan WF, Goedhart ZD. Shunting normalpressure hydrocephalus: do the benefits outweigh the risks? A multicenter study and literature review. Neurology. 1992;42:54-9.

10. Weiner HL, Constantini S, Cohen H, Wisoff JH. Current treatment of normalpressure hydrocephalus: comparison of flow-regulated and differentialpressure shunt valves. Neurosurgery. 1995;37:877-84.

11. Marmarou A, Bergsneider M, Klinge P, Relkin N, Black PM. The value of supplemental prognostic tests for the preoperative assessment of idiopathic normal-pressure hydrocephalus. Neurosurgery. 2005;57(3 Suppl ):S17-28; discussion ii-v.

12. Relkin N, Marmarou A, Klinge P, Bergsneider M, Black PM. Diagnosing idiopathic normal-pressure hydrocephalus. Neurosurgery. 2005;57(3 Suppl):S4-16; discussion ii-v.

13. Brean A, Eide PK. Prevalence of probable idiopathic normal pressure hydrocephalus in a Norwegian population. Acta Neurol Scand. 2008;118:48-53.

14. O'Kane MC, Richards H, Winfield P, Pickard JD. The United Kingdom Shunt Registry. Eur J Pediatr Surg. 1997;7(Suppl 1):56.

15. Kestle J, Drake J, Milner R, Sainte-Rose C, Cinalli G, Boop F, et al. Long-term follow-up data from the shunt design trial. Pediatr Neurosurg. 2000;33:230-6.

16. Pinto FC, Saad F, de Oliveira MF, Pereira RM, de Miranda FL, Tornai JB, et al. Role of endoscopic third ventriculostomy and ventriculoperitoneal shunt in idiopathic normal pressure hydrocephalus: preliminary results of a Randomized Clinical Trial. Neurosurgery. 2013;72:845-54

17. Zemack G, Romner B. Adjustable valves in normal-pressure hydrocephalus: a retrospective study of 218 patients. Neurosurgery. 2002;51:1392-400; discussion 1400-2.

18. Ishikawa M, Hashimoto M, Kuwana N, Mori E, Miyake H, Wachi A, et al. Guidelines for management of idiopathic normal pressure hydrocephalus. Neurol Med Chir (Tokyo). 2008;48(Suppl):S1-23.

19. Mori K. Management of idiopathic normal-pressure hydrocephalus: a multiinstitutional study conducted in Japan. J Neurosurg. 2001;95:970-3.

20. Shprecher D, Schwalb J, Kurlan R. Normal pressure hydrocephalus: diagnosis and treatment. Curr Neurol Neurosci Rep. 2008;8:371-6.

21. Kazui H, Mori E, Hashimoto M, Ishikawa M, Hirono N, Takeda M. Effect of shunt operation on idiopathic normal pressure hydrocephalus patients in reducing caregiver burden: evidence from SINPHONI. Dement Geriatr Cogn Disord. 2011:31:363-70.

22. Eide PK, Sorteberg W. Changes in intracranial pulse pressure amplitudes after shunt implantation andadjustment of shunt valve opening pressure in normal pressure hydrocephalus. Acta Neurochir (Wien). 2008;150:11417; discussion 1147.

23. Bakker SL, Boon AJ, Wijnhoud AD, Dippel DW, Delwel EJ, Koudstaal PJ. Cerebral hemodynamics before and after shunting in normal pressure hydrocephalus. Acta Neurol Scand. 2002;106:123-7.

24. Freimann FB, Streitberger KJ, Klatt D, Lin K, McLaughlin J, Braun J, et al. Alteration of brain viscoelasticity after shunt treatment in normal pressure hydrocephalus. Neuroradiology. 2012;54:186-96.

25. Carmel PW, Albright AL, Adelson PD, Canady A, Black PMcL, Boydston W, et al. Incidence and management of subdural hematoma/hygroma with variable- and fixed-pressure differential valves: A randomized, controlled study of programmable compared with conventional valves. Neurosurg Focus. 1999;7:e7.

26. Reinprecht A, Czech T, Dietrich W. Clinical experience with a new pressureadjustable shunt valve. Acta Neurochir (Wien). 1995;134:119-24

27. Zemack G, Romner B. Seven years clinical experience with the Codman Hakim programmable valve: a retrospective study of 583 patients. J Neurosurg. 2000;92:941-8.

28. Meier U, Lemcke J. First clinical experiences in patients with idiopathic normal-pressure hydrocephalus with the adjustable gravity valve manufactured by Aesculap (proGAV(Aesculap)). Acta Neurochir Suppl. 2006;96:368-72.

29. Kestle JR, Walker MLJ. A multicenter prospective cohort study of the Strata valve for the management of hydrocephalus in pediatric patients. Neurosurgery 2005;102(2 Suppl):141-5.

30. Chan AK, McGovern RA, Zacharia BE, Mikell CB, Bruce SS, Sheehy JP, et al. Inferior short-term safety profile of endoscopic third ventriculostomy compared with ventriculoperitoneal shuntplacement for idiopathic normalpressure hydrocephalus: a population-based study. Neurosurgery. 2013;73:951-60; discussion 960-1.

31. Kondageski C, Thompson D, Reynolds M, Hayward RD. Experience with the Strata valve in the management of shunt overdrainage. J Neurosurg. 2007;106(2 Suppl):95-102.

32. Ahn KJ, Koh HS, Kim SH, Youm JY, Song SH, Kim Y. Clinical analysis of programmable valve versus differential pressure valve in hydrocephalus. J Korean Neurosurg Soc. 2003;34:230-3

33. Lundkvist B, Koskinen LO, Birgander R, Eklund A, Malm J. Cerebrospinal fluid dynamics and long-term survival of the Strata valve in idiopathic normal pressure hydrocephalus. Acta Neurol Scand. 2011;124:115-21.

34. Hamilton R, Patel S, Lee EB, Jackson EM, Lopinto J, Arnold SE, et al. Lack of shunt response in suspected idiopathic normal pressure hydrocephalus with Alzheimer disease pathology. Ann Neurol. 2010;68:535-40.

35. Hebb AO, Cusimano MD. Idiopathic normal pressure hydrocephalus: a systematic review of diagnosis and outcome. J Neurosurg. 2001; 49:1166-84

36. Pujari S, Kharkar S, Metellus P, Shuck J, Williams MA, Rigamonti D. Normal pressure hydrocephalus: long-term outcome after shunt surgery. J Neurol Neurosurg Psychiatry. 2008;79:1282-6.

37. Ziebell M, Wetterslev J, Tisell M, Gluud C, Juhler M. Flow-regulated versus differential pressure-regulated shunt valves for adult patients with normal pressure hydrocephalus. Cochrane Database Syst Rev. 2013;5:CD009706

38. Meier U, Stengel D, Müller C, Fritsch MJ, Kehler U, Langer N, et al. Predictors of subsequent overdrainage and clinical outcomes after ventriculoperitoneal shunting for idiopathicnormal pressure hydrocephalus. Neurosurgery. 2013;73:1054-60

39. Lemcke J, Meier U. Improved outcome in shunted iNPH with a combination of a Codman Hakim programmable valve and an Aesculap-Miethke Shunt Assistant. Cent Eur Neurosurg. 2010;71:113-6.

40. Gomes Pinto FC, de Oliveira MF. Response to journal club: role of endoscopic third ventriculostomy and ventriculoperitoneal shunt in idiopathic normal pressure hydrocephalus: preliminary results of a randomized clinical trial Neurosurgery. 2013;73:911-2.

41. Chrissicopoulos C, Mourgela S, Kirgiannis K, Sakellaropoulos A, Ampertos $\mathrm{N}$, Petritsis K, et al. What is the appropriate shunt system for normal pressure hydrocephalus? Acta Neurochir Suppl. 2012;113:119-21.

42. Delwel EJ, de Jong DA, Dammers R, Kurt E, van den Brink W, Dirven CM. A randomised trial of high and low pressure level settings on an adjustable ventriculo peritoneal shunt valve for idiopathic normal pressure hydrocephalus: results of the Dutch evaluation programme Strata shunt (DEPSS) trial. J Neurol Neurosurg Psychiatry. 2013;84:813-7.

43. Mpakopoulou M, Brotis AG, Gatos H, Paterakis K, Fountas KN. Ten years of clinical experience in the use of fixed-pressure versus programmable valves: a retrospective study of 159 patients. Acta Neurochir Suppl. 2012;113:25-8

44. Ringel F, Schramm J, Meyer B. Comparison of programmable shunt valves vs standard valves for communicating hydrocephalus of adults: a retrospective analysis of 407 patients. Surg Neurol. 2005;63:36-41; discussion 41.

45. Oliveira MF, Saad F, Reis RC, Rotta JM, Pinto FC. Programmable valve represents an efficient and safe tool in the treatment of idiopathic normalpressure hydrocephalus patients. Arq Neuropsiquiatr. 2013;71:229-36. 